move to community psychiatry and in the case of NHS consultants operating in other administrative contexts, e.g. child guidance clinics.

Council recommended that this whole area should be kept very much under surveillance, perhaps through the Public Policy Committee. Members in difficulty should be offered guidance on request.

\section{Continuing education}

The Consultant is likely to take a more critical view of his up-to-date competence under the stimulus of medical audit, the Health Advisory Service and the Mental Health Act Commission. The need is very clearly felt and articulated throughout the College for continuing education.

Concern has been expressed for consultants working in isolated situations who might be hard pressed clinically, perhaps working without trainees, the very people who need an educational stimulus. Pressure for adequate staffing levels in this context is imperative.

There was little support for mandatory requirements for attendance at educational events; for taking up study leave and sabbatical leave. Medical audit, however, was seen as an important educational vehicle-regular peer review, e.g. at admission and discharge conferences; meetings to assess episodes of suicide or violence, perhaps under the auspices of Cogwheel Divisions.

Council endorsed the following recommendations:

(a) The College should take a major initiative in the field of continuing education.

(b) The Education and Programmes and Meetings Committees should review the issue and make proposals. The College, for example, might arrange regular meetings designed for consultants to include reviews of recent developments in psychiatry; teaching methodology and sessions devoted to special interests. The surroundings should be pleasant and conducive to relaxed, social contacts.

(c) Chairmen of Divisions and Sections should be sensitized to the need for initiative in continuing education, e.g. in setting up local programmes, perhaps in concert with academic departments.

\title{
The Responsibilities of Consultants in Psychiatry within the National Health Service
}

This document, originally published in the Bulletin, September 1977, is now reprinted on the instructions of Council. The reasons for this decision are incorporated in the fourth section of the paper by me, "The Future of the Consultant in Psychiatry', which appears in this issue.

Council has reaffirmed its support for the value of multidisciplinary team working in clinical practice, while remaining conscious of the difficulties that may arise in particular specialties and in certain administrative contexts.

Council has been greatly exercised by problems of confidentiality in the team setting, especially where information may pass to agencies outside Health Services jurisdiction. Attempts are being made at various levels to resolve these issues.

\section{K. RAWNSLEY}

The following report has been adopted as College policy by Council. The need for this arose from a number of sources: statements contained within the published Reports of Committees of Inquiry and requests from other professional bodies and from members of the College and others. At the same time it was necessary to outline the College's policy in regard to the multidisciplinary team concept and to relate consultant responsibility within that framework.

The responsibilities of a Consultant Psychiatrist are similar to those of other consultants within the National Health Service. The few differences arise from the special circumstances within the specialty, particularly relationships with other disciplines. The ability of Consultants to accept medical responsibility rests on their training, qualifications and statutory responsibility. Medical qualifications carry professional, ethical and legal responsibilities. These responsibilities are exercised towards and given by the public; are aimed at the cure or alleviation of human suffering; are independent of remuneration; and follow the medical practitioner wherever he may be, even within his private life.

In common with all medical practitioners, the Consultant is governed and licensed to act by Parliament. The Medical Acts govern the conditions under which the public can recognize and expect a basic standard of treatment for illness. Within these Acts the governing bodies for standards are set up, and the General Medical Council supervises the standards of training in medical schools, maintains a Register of recognized practitioners, and enforces an ethical code through its disciplinary body. This body exercises an ultimate power to remove the name of the doctor from the professional Register. From a doctor's point of view, this power represents an ultimate discipline and deterrent, and the medical profession operates within this framework of governed professionalism. It is a personal matter for doctors to uphold standards within this framework. They must act within their own professional conscience arising from the confidential relationship with the patient and within the limits set by law and society. It also leads to the insistence by 
doctors on retaining their professional freedom to act in the interests of their patients. Doctors relate to each other from the same background and it is difficult to direct matters of clinical opinion and conscience. Medical staffing structures are only loosely hierarchical, even in the Hospital Service.

The Consultant represents ultimate medical authority within the Hospital Service for patients in his care. There are no senior medical opinions that can override a medical opinion held at this level. The employer has no powers in this aspect of professional judgement. Questions of incompetence or negligence in a professional sense are a matter for the Courts or the General Medical Council.

Professional functioning is a primary concern of other long-recognized professions that deal with confidential and private matters of citizens, most of which have developed codes of practice. All these professions, including the medical professions, insist on professional freedom, whilst at the same time accepting a self-imposed discipline and responsibility dictated by the professional conscience. Authority to practise is usually given by the public through Acts of Parliament and controlled in each case by independent professional governing bodies. All these professions prescribe a long undergraduate and postgraduate training before the individual can assume ultimate professional authority and responsibility. This is the case for a Consultant in the National Health Service, where there has been six years' undergraduate and some ten years' postgraduate experience. It is generally required for the doctor to have obtained in most cases two registrable qualifications. There are few areas of human endeavour where such long apprenticeship is required, and where there are so many obstacles to achieving the position.

Once a practitioner has been accepted on the Registrar to practise by the General Medical Council, he is licensed to operate at an individual level and charged to behave as described above to required professional and ethical standards. Junior medical staff must, therefore, be seen as competent professionals capable of independent action. They continue to mature with increasing experience following registration, and this is the main difference between the junior medical staff and Consultants. Consultants represent the most senior and experienced opinion in the hospital service, but theirs is not the only opinion. When allocated junior or assistant staff, Consultants have overall responsibility for the work load and have to decide what medical duties they assign to the junior staff. This they do in negotiation with the junior staff and they indicate how far and to what extent the junior staff may operate. Junior doctors, if they do not feel able to accept responsibility for individual cases, must refer them to the Consultant, who must then accept final responsibility.

The training, selection procedures and qualification necessary to assume Consultant status is of a high order. Consultant status within the National Health Service is created by the National Health Service Act, 1946, and the Advisory Appointments Committee procedure arises from this Act. Other disciplines within the National Health Service are not so clearly legally defined. This arises from the nature of medical responsibility and is to ensure for the public adequate specialist consultant standards. In practice, the Advisory Appointments procedure is the single most important step from the employer's point of view, for, once the appointment has been made, the employer has limited control over the professional opinions of the individual Consultant.

The Consultant has, by virtue of professional qualification, Acts of Parliament and contract, the authority and responsibility to diagnose and prescribe medical treatment, and this responsibility cannot be wholly devolved elsewhere. These powers and responsibilities are central to any Consultant appointment and vary with each specialty only as to what the details of the diagnostic or prescriptive procedures may be and as to how far the executive actions of treatment are individually operated by medical personnel.

\section{Multidisciplinary functioning}

In the Hospital Service the Consultant associates with a variety of other disciplines of widely differing professional status. These relationships have been subject to considerable publicity and discussion in recent years under the general title of 'multidisciplinary teams', particularly when dealing with in-patients at ward level. The multidisciplinary policy is being stressed throughout the Service particularly in relation to the long-stay specialties; the emphasis being less in the general specialties. The policy generally lacks clarity and is liable to different interpretation, depending on the point of view of the particular discipline. By some it is thought of as a 'democratic way' of arriving at the best method of treating patients, whilst in others it is regarded as giving the status of equality in all matters to each member of the team. There is confusion between team-functioning of disciplines at management and administrative levels, and team-functioning at clinical levels. Administrative or management issues can be decided on a corporate basis because the standing between the disciplines is on a basis of equality in arriving at a management decision. This method generally cannot be applied to professional opinions relating to individual patients. The confusion rests on the validity of corporate decisions as opposed to individual professional decisions.

The legal, professional, ethical, diagnostic and prescriptive responsibilities of the medical profession cannot be delegated to a multidisciplinary group when treating an individual patient. Each doctor (Consultant) must formulate his own opinion, whether assisted in this process by others or not. Multidisciplinary in this context, from the medical point of view, is a process of consultation, the final decision resting with the Consultant on matters where the Consultant has the final responsibility. Similar conditions may apply to other professions when the central responsibilities germane to these disciplines are involved. However, with patients the 
medical role is the prime mover for the whole process of treatment and care. In the multidisciplinary team model that is being put forward, a standardized pattern centring on a regular meeting on the ward of all disciplines is recommended. This model is being transmitted throughout the Service to the extent that there is an implication that if meetings are not held, there is some failure of those involved. It must be stated that communications at ward level and the formation of the team spirit are important to the care of patients, but it does not necessarily follow that there is only one method (through a meeting) by which communications can be achieved; nor does it follow that if meetings were held widely throughout the Service they would necessarily achieve the expected results. Age, experience of participants, personalities, local factors, professionalism, structure of disciplines within the hospitals and administrative policies all militate both for and against relationships and communication.

The relationship of hierarchical management to multidisciplinary teams at ward level is not clear. Some disciplines are governed by a hierarchical structure, for example, nursing and social work, where each tier has contractual authority over the lower tiers. In this hierarchical structure it is not always clear whether the authority is clinical or administrative, or both. If a multidisciplinary team agree what is best for their patient or ward, can a senior officer of one discipline put aside the decision of the team? Can the authority of any one person override the team decision? Has a team decision any real authority when opposed to hierarchical management authority? If it has, then there will have to be changes in hierarchical management authority, both in structure, contract and philosophy. True multidisciplinary team work at clinical levels can be recommended as probably the most efficient way of staff cooperation in the treatment of patients only provided that each member of the team is given full powers to make decisions. This implies that hierarchical disciplines should decentralize their powers to their members of the teams of the same order as that of the medical profession.

Whilst employing authorities may express views on good practice to obtain improved care of patients, they can only express an opinion. There is no way to legislate on how a variety of differing disciplines can or should relate to each other. The issue is too complex, and successful relationships only occur where the local personalities allow their development. The present policy of multidisciplinary functioning is creating uncertainty and interferes with interprofessional relationships which may have evolved over many years and which have always been flexible. The multidisciplinary concept can be introduced in an ill-considered way; it can be too idealistic; in many situations it is impracticable; and it may ignore professional responsibilities. In these circumstances the policy can only be expected to function in most hospitals partially, and in some areas it may even be disruptive and counterproductive.
Multidisciplinary team functioning should be seen as an option, not as a rigid pattern, and there should be discretion at ward level. Administrative/management staff of all disciplines will have to be prepared to modify their approach to their colleagues who are in a clinical relationship to patients. Depending on relationships between the disciplines, Management will have to either respect the team and its democracy where it exists, or play the more authoritarian hierarchical role where other relationships exist. In a Service as large as the National Health Service there can be no standard rules, and flexibility of administration is indicated.

\section{The Consultant's responsibilities}

(1) The first responsibility of a Consultant is, as a doctor, to his patient, and is governed by a confidential relationship within the limitations prescribed by the law of the land and society.

(2) The second responsibility is to maintain the ethical standards of his profession. This is governed by an ethical code interpreted by professional bodies who carry the sanction to discipline professional behaviour.

(3) There is a responsibility to bring to any patient the best available treatment within his experience and to act within his professional conscience and opinion in the interests of the patient.

(4) The National Health Service Act gives the consultant legal powers to provide the public with a professional service, the standards of which are governed by the Advisory Appointments procedure. This recognizes that the Consultant is the ultimate medical opinion and as such autonomous within the professional framework described above. The Consultant is responsible to his employers in all matters, except clinical professional standards and responsibilities, where he is responsible elsewhere. The Minister is not responsible for matters of professional opinion or treatment of individual patients but is responsible for providing the service (NHS Act 1973 Section 2(2)).

(5) The responsibilities and powers of the medical profession and, therefore, Consultants are laid out in Acts of Parliament and as defined by the various working parties over the years (Spens, Platt and Godber).

'A Consultant is a doctor appointed in open competition by a statutory hospital authority to permanent staff status in the Hospital Service after completing training in a specialty and, in future, being included in the appropriate vocational register; by reason of his training and qualifications he undertakes full responsibility for the clinical care of his patients, without supervision in professional matters by any other person; and his personal qualities and other abilities are pertinent to the particular post.' (Report of the Godber Working Party, DHSS, 1969.)

(6) A Consultant has the ultimate responsibility and the overall authority to diagnose illness and prescribe treatment. This authority may be delegated, but the responsibility can- 
not be abrogated. In view of the high cost and complexity of modern medical treatment, there is a responsibility and duty to be concerned in the administrative processes of the National Health Service and to play an active role in ensuring that resources are used with efficiency and economy.

(7) The Consultant has a direct responsibility to see that the variety of disciplines caring for patients are co-ordinated and used effectively to pursue the major objective of the best treatment of the individual patient in his medical care. This implies leadership of the multidisciplinary teams dealing with clinical problems and accepting the responsibilities of leadership.

(8) The Consultant has a responsibility to ensure that any junior medical staff assigned to him are not delegated duties which they are unable to execute efficiently. He has a responsibility to take part in their training, including their clinical teaching.

(9) He has a responsibility towards the community he serves via the general practitioner, who he must ensure is kept fully informed. While the patient is in hospital the clinical responsibility lies with the Consultant. The general overall medical care of out-patients remains the on-going responsibility of the general practitioner, the Consultant acting in an advisory capacity or providing specialized treatment.

(10) The Consultant has the power and responsibility to determine the clinical needs of an individual patient and the appropriate care required. Thus he decides whether the patient should receive in-patient, out-patient, or day care, and will admit or discharge patients as appropriate. The National Health Service Act empowers the Minister (and hence the Administration) to provide the service and its associated facilities, and to appoint professional staff (NHS Act 1973, Section 2(2); Section 7(1) and (2); Mental Health Act 1959, Section 59(1)). The area of influence of an individual Consultant is laid down in the contract and terms and conditions of service. The Consultant has a duty to see and care for patients as laid down by contract, but is independent as regards his opinion as to the needs of the patient.

(11) Consultants are accountable for their decisions and actions in two ways. Firstly, to their employer and management for their general conduct in ordinary employment and non-professional issues; they can be held responsible for executing decisions of management as they properly apply to them. Secondly, in professional judgements they answer to the Courts or the General Medical Council and are not ultimately responsible to the employer or management. For this reason each Consultant must accept responsibility for his own legal defence in the event of any action against him. These professional opinions may, however, concern management or their clinical colleagues and the Consultant can be subject to inquiry as to the results of his opinion when it affects others. The Merrison Committee has made recommendations regarding competence to practise; the Davies Committee as regards complaints procedures; and for some years the practice of peer review by the 'three wise men' procedure has operated (HM(60)45).

(12) The Consultant has a responsibility, being the arbiter of the care of patients, to draw attention of management to deficiencies in the service and facilities. This is particularly so if the deficiency prevents him from properly carrying out his ethical and clinical duties towards his patients.

(13) Consultants in psychiatry have special responsibilities in relation to the Mental Health Act to undertake the duties and powers given to the Responsible Medical Officer within the Act.

(14) In common with all doctors, the Consultant has to preserve confidentiality of personal information entrusted to him by patients. This applies to written or oral information obtained within the doctor-patient relationship. The situation is complicated, since Hospital case notes are the responsibility of the Secretary of State. The College has recently issued a memorandum giving guidance about confidentiality (News and Notes, January 1977).

\section{Conclusion}

This memorandum outlines the responsibilities of the Consultant Psychiatrist. It presents the view of the Royal College of Psychiatrists on the main responsibilities. Comment is made regarding multidisciplinary team functioning and a plea entered for the policy to be flexible, and that there should be no standard rules. The responsibilities of the Consultant grade as set out must not be taken as comprehensive, but are offered as broad guidelines.

\section{Retirement and Temporary Retirement- Subseriptions}

At its meeting in January 1984 the Executive and Finance Committee authorized the Treasurer to use his discretion to allow 'retirement rates' for subscriptions if he felt this was justified. As a guideline it was suggested that 'retirement' would mean that a member was not engaged in any significant employment, medical or otherwise.
The Treasurer had also been made aware of difficulties encountered by some members who were, for instance, temporarily unable to work or were caring for a young family, and was authorized to use his discretion to allow a temporary retirement rate of subscription when he felt this was appropriate. 